\title{
Is Ultrasound out of Control?
}

\author{
Adnan Kabaalioğlu
}

Akdeniz University Medical Faculty, Department of Radiology, Antalya Turkey

Some people might think that the title is a negative one because so many doctors and technicians are practising ultrasound (US) worldwide, and not all of them are experts. Many national and international medical ultrasound societies such as EFSUMB, WFUMB, AIUM and SRU are trying to control the use of US, by advising that only appropriately educated medical staff should do the US exams. In the past, formal US education was mostly limited to the radiology departments. Ultrasound's great capability of real-time, high quality and portable imaging made a revolutionary change in diagnosis and differential diagnosis of many diseases. Color Doppler mode and guidance for interventions have been additional powers of US. The fast enlarging spectrum and increasing use of US, has taken it beyond the borders of radiology. It has become an essential tool in the emergency and operating rooms as well as in intensive care units. This diffusion of US to many diverse settings may be seen as the positive side of "being out of control". We do not need to control the widespread use of US: however, we need to keep updated at least in our daily focused US practice. Medical US societies should continue to suggest rules, guidelines, e-learning tools, hands-on courses and similar activities to prevent the "out of control" practice of US. We all know that if US is performed by the untrained or with commercial concerns, the results for the patients and the health economy, would be unacceptable.

One of the issues in US education is the incorporation of US into medical student education. During my intern-

Received Accepted

Med Ultrason

2014, Vol. 16, No 3, 283-284

Corresponding author: Prof. Dr. Adnan Kabaalioğlu

Akdeniz University Medical Faculty

Department of Radiology

Antalya-Turkey

e-mail: adnank@akdeniz.edu.tr ship in medical school I never heard of US, and I still remember that we practised a lot to detect organ enlargements (liver, spleen and even heart) by percussion and palpation. Now, it is much more easy and more accurate with US. Why do students not take advantage of this? It has been demonstrated that, for the detection of several cardiac pathologies, a trained medical student using US is usually more accurate than an experienced physician who is doing only a physical examination [1].

In recent years, US training for medical students has been integrated into the curriculum: University of South Carolina, California and Harvard Medical School are examples from the United States, with pilot projects in progress $[2,3]$. Several studies have shown that students have been eager to participate in US trainings and most of them considered this an important part of their future life [4]. Similar applications have been considered necessary for residency programmes. However, several problems related to US training have also been emphasized in recent papers and these can be listed as:

1. Many experts are concerned about adding new contents to an already voluminous curricula of medical education [5],

2. There is a need to buy new equipment, exam beds, and other accessories to maintain the service,

3. There should be a specific location to organise the hands-on teaching. Should this be a new department or should this be embedded in anatomy, radiology, internal medicine or medical education departments?

4. Extra time and money is required to organise a permanent teaching faculty,

5. The knowledge diminishes over time; therefore, the training should be continuous [6].

Still, there remains other issues related to "out of control" use of ultrasound. If a doctor has to examine 80-100-120 patients a day, is the education enough to overcome the quality problem? Certainly no; in some 
countries like mine, many doctors face the problem of an over-dose of patient numbers. If a doctor cannot talk with a patient before and after the US scanning, and does not have time to check the clinical and laboratory findings, or previous imaging findings, how much impact can that doctor make? Or is this fast service any different than that of a technician-sonographer? It is certain that if a doctor has to perform more than 40-50 US examinations a day, the work he or she has done may rather be labeled as "out of control"!

\section{References}

1. Kobal SL, Trento L, Baharami S, et al. Comparison of effectiveness of hand-carried ultrasound to bedside cardiovascular physical examination. Am J Cardiol 2005; 96:1002-1006.
2. Hoppmann R, Cook T, Hunt P, et al. Ultrasound in medical education: A vertical curriculum at the University of South Carolina School of Medicine. JSC Med Assoc 2006; 102: 330-334.

3. Solomon SD, Saldana F. Point-of-care ultrasound in medical education-stop listening and look. N Engl J Med 2014; 370: 1083-1085.

4. Mircea PA, Badea R, Fodor D, Buzoianu AD. Using ultrasonography as a teaching support tool in undergraduate medical education-time to reach a decision. Med Ultrason 2012; 14: 211-216.

5. Bahner DP, Goldman E, Way D, Royall NA, Liu YT. The State of Ultrasound Education in U.S. Medical Schools: Results of a National Survey. Acad Med 2014 DOI 10.1097/ ACM.0000000000000414

6. Dulohery MM, Stoven S, Kurlinsky AK, Halvorsen A, Mc Donald FS, Bhagra A. Ultrasound for internal medicine physicians: the future of the physical examination. J Ultrasound Med 2014; 33: 1005-1011. 